\title{
When lockdown policies amplify social inequalities in COVID-19 infections: evidence from a cross-sectional population- based survey in France
}

Nathalie Bajos ${ }^{1 *}$ (D, Florence Jusot ${ }^{2}$, Ariane Pailhé3 ${ }^{3}$, Alexis Spire ${ }^{4}$, Claude Martin ${ }^{4}$, Laurence Meyer ${ }^{5}$, Nathalie Lydié 6 , Jeanna-Eve Franck ${ }^{1}$, Marie Zins ${ }^{7}$, Fabrice Carrat $^{7}$ for the SAPRIS study group

\begin{abstract}
Background: Significant differences in COVID-19 incidence by gender, class and race/ethnicity are recorded in many countries in the world. Lockdown measures, shown to be effective in reducing the number of new cases, may not have been effective in the same way for all, failing to protect the most vulnerable populations. This survey aims to assess social inequalities in the trends in COVID-19 infections following lockdown.

Methods: A cross-sectional survey conducted among the general population in France in April 2020, during COVID-19 lockdown.

Ten thousand one hundred one participants aged 18-64, from a national cohort who lived in the three metropolitan French regions most affected by the first wave of COVID-19.

The main outcome was occurrence of possible COVID-19 symptoms, defined as the occurrence of sudden onset of cough, fever, dyspnea, ageusia and/or anosmia, that lasted more than 3 days in the 15 days before the survey. We used multinomial regression models to identify social and health factors related to possible COVID-19 before and during the lockdown.

Results: In all, 1304 (13.0\%; 95\% Cl: 12.0-14.0\%) reported cases of possible COVID-19. The effect of lockdown on the occurrence of possible COVID-19 was different across social hierarchies. The most privileged class individuals saw a significant decline in possible COVID-19 infections between the period prior to lockdown and during the lockdown (from 8.8 to $4.3 \%, P=0.0001$ ) while the decline was less pronounced among working class individuals (6.9\% before lockdown and 5.5\% during lockdown, $P=0.03$ ). This differential effect of lockdown remained significant after adjusting for other factors including history of chronic disease. The odds of being infected during lockdown as opposed to the prior period increased by $57 \%$ among working class individuals $(\mathrm{OR}=1.57 ; 95 \% \mathrm{Cl}: 1.00-2.48)$. The same was true for those engaged in in-person professional activities during lockdown (OR=1.53; 95\% Cl: 1.03-2.29).

(Continued on next page)
\end{abstract}

\footnotetext{
* Correspondence: nathalie.bajos@inserm.fr

'Institut de Recherche Interdisciplinaire sur les enjeux Sociaux - Sciences sociales, politique, santé, IRIS (UMR 8156 CNRS - EHESS - U997 INSERM), 5 cours des humanités, 93322 Aubervilliers, France

Full list of author information is available at the end of the article
}

(c) The Author(s). 2021 Open Access This article is licensed under a Creative Commons Attribution 4.0 International License, which permits use, sharing, adaptation, distribution and reproduction in any medium or format, as long as you give appropriate credit to the original author(s) and the source, provide a link to the Creative Commons licence, and indicate if changes were made. The images or other third party material in this article are included in the article's Creative Commons licence, unless indicated otherwise in a credit line to the material. If material is not included in the article's Creative Commons licence and your intended use is not permitted by statutory regulation or exceeds the permitted use, you will need to obtain permission directly from the copyright holder. To view a copy of this licence, visit http://creativecommons.org/licenses/by/4.0/. The Creative Commons Public Domain Dedication waiver (http://creativecommons.org/publicdomain/zero/1.0/) applies to the data made available in this article, unless otherwise stated in a credit line to the data. 
(Continued from previous page)

Conclusions: Lockdown was associated with social inequalities in the decline in COVID-19 infections, calling for the adoption of preventive policies to account for living and working conditions. Such adoptions are critical to reduce social inequalities related to COVID-19, as working-class individuals also have the highest COVID-19 related mortality, due to higher prevalence of comorbidities.

Keywords: Social inequalities, Lockdown, COVID-19, General population, Risk factors

\section{Introduction}

Given the pre-existing social inequalities in health within societies [1] and the significant differences in COVID-19 mortality by gender, class and origin recorded in countries such as France [2, 3], the United Kingdom [4], the USA [5] and other countries around the world [6], several studies address issues of social inequalities related to COVID-19 [7-11]. However, to our knowledge, no study has investigated potential social inequalities in the effects of lockdown policies, widely implemented around the globe.

Our hypothesis is that lockdown measures, shown to be effective in reducing the number of new cases [12], have not been effective in the same way for all, failing to protect the most vulnerable populations. While more privileged social classes may have had greater exposure to the virus prior to lockdown, due to more frequent social interactions in public spaces (e.g. bars, restaurants) and travelling, they may have better adapted to lockdown measures, through telework, while working classes may have benefited less from lockdown conditions, due to their professional obligations as essential workers and their living conditions in overcrowded housing.

Our objective was to study the differential effect of lockdown measures on possible COVID-19 infections according to social class in France, one of the most affected countries in Europe by the first wave of COVID-19.

\section{Methods}

\section{Study design and participants}

The SAPRIS (SAnté, Pratiques, Relations et Inégalités Sociales en population générale pendant la crise COVID19) survey was set-up mid-March 2020, with the general aim of understanding the main epidemiological, social and behavioural challenges of the SARS-CoV2 epidemic in France [13]. It relies on a consortium of five prospective population-based cohort. The analysis presented here is based on data from one of the three adult cohorts, the Constances cohort, which is the only cohort to have accurate data on professional status and preventive measures in the workplace. Constances is a generalist cohort made up of a national sample of 215,000 adults aged 18 to 69 at inclusion and recruited from 2012 onwards [14].

All cohort members of Constances who had regular access to the internet $(n=66,848$ ) were invited to complete the SAPRIS questionnaire online. $69.0 \%$ participated in the survey $(46,107)$. To best highlight the impact of the lockdown on possible COVID-19 symptoms, we chose to center this analysis on individuals (18-64 years) who have already been employed, living in one of the three metropolitan French regions most affected by the first wave of COVID-19 i.e. Grand Est, Ile-de-France (Paris Region) and Hauts-de-France. Ten thousand one hundred one participants met this criteria and were included in the analysis.

Data were collected in accordance with the Declaration of Helsinki. Ethical approval and written informed consent was obtained from each participant to be included in the initial cohort in 2015. In accordance with French law, this nested survey, based on an ad hoc COVID-19 questionnaire administered in 2020 to cohort participants, did not require any specific additional written consent from the participant. This nested COVID-19 survey has been approved by the Inserm ethics review committee (approval no. 20-672 of March 30, 2020).

\section{Data collection}

Data collected online from April 6th to May 5th, 2020 solicited information on socio-demographic characteristics, household size and composition, employment characteristics, daily life conditions, childcare arrangements, alcohol and tobacco use, sexual life, comorbidities, health care utilization and treatments. The questionnaire also addressed COVID-19 related topics including preventive behaviors (gel, mask, social distancing) for individuals and in the workplace, risk perceptions and COVID-19 related beliefs as well as a detailed description of COVID-19 symptoms over the last 2 weeks.

Symptoms were reported if they were unusual and occurred at least once in the past 2 weeks ("In the last two weeks, including today, have you had any of the following symptoms that you do not usually have: fever/cough/difficulty breathing/twitching of taste or smell ..."). The duration of symptoms were graded on a scale of one to five (less than 1 day, 1 to 3 days, 4 to 7 days, 8 to 14 days, $>14$ days). Finally, the total time (in days) between the onset of the first symptom and the date of the survey was reported.

\section{Measures}

Our main outcome was a three-category measure, distinguishing 1) No suspicion of Covid-19 infection, 2) probable infection before the lockdown and 3) probable infection 
during the lockdown. We used the following criteria defined by the European Centre for Disease Prevention to identify "possible COVID-19 infection: at least cough or fever or dyspnea or sudden onset of ageusia, dysgeusia or anosmia occurring during the at-risk period" [15]. We added an additional criterion of duration, including symptoms lasting more than 3 days to add additional specificity to our definition [16].

As underlined by McAloon and colleagues, the choice of which parameter values are adopted depends on how the information is used, the associated risks and the perceived consequences of decisions to be taken [17]. In France, the incidence of the first wave was estimated to be highest around the 19th of March - during the first week of the lockdown - and rapidly decreased right after [15]. Therefore, the probability of having been infected by the COVID-19 was higher before rather than during the lockdown. The period of incubation was chosen to be 7 days (the 75 th percentile of the incubation period [18]) in order to class the individuals which have had their symptom(s) on the first week of the lockdown in the "likely infection prior lockdown" group, according to the higher probability of having been infected before rather than during the lockdown.

The likely period of infection (LPC) was identified as a function of $i$ ) the duration between the onset of the first symptoms and the date of the survey (DFS), ii the duration of incubation (DI) of 7 days [16] and iii) the date of survey (DS). LPS was defined as follows:

$$
L P C=D S-(D F S+D I)
$$

Based on this information probable infection before the lockdown included LPC before March 17th while infection during the lockdown included LPC on or after March 17th.

Participants' social position was defined according to 3 criteria: current professional status (Inactive, retired or unemployed before the beginning of the pandemic/ employed but stopped working since the beginning of the pandemic / Full-time teleworking / Full-time or part-time in-person professional activities), social class and financial situation as perceived by respondents (comfortable/no problems/difficult). Social class was based on current or previous occupation, and distinguished health professions with specific exposure to the virus. The following 5 categories were constructed: Health professionals (doctors, nurses, caregivers), Upper class (senior managers), High middle class (intermediate professions), Low middle class (employees and skilled workers with a diploma of higher or equal to 2 years university degree), working class (unskilled employees and workers with a diploma lower than a 2years university degree).

\section{Statistical methods}

We used inverse probability weighting to correct for selection and non-participation biases. The Constances cohort includes a randomly selected representative sample of the French adult population and is affiliated to the General Health Insurance Fund (the source population, that is, approximately $85 \%$ of the total French population [14]. By January 2020, 204,973 participants had been recruited in the Constances cohort, 66,848 were regular internet users and were invited to the survey and 46,107 did participate. Our sampling weights had the objectives to adjust for selection (66,848 among 204,973) and participation/non-response (46,107 among 66,848). Sampling weights were estimated by two different logistic regression models, with selection or participation as the response variables and with participant characteristics collected before the survey from all cohort participants (Region, Rural/Urban living, age, sex, socio-professional category, educational level, number of people living in the household, BMI, smoking, perceived health, comorbidities) as covariates. The weight adjusted on selection and participation (range: 2.75-7.32) was obtained from the product of weights estimated from the selection (range: 2.08-8.65) and participation (range: 1.15-2.49) regression models.

Then calibration of these weights was performed by generalized raking [19] in relation to the marginal totals of the age-class, gender and socio-professional-category distributions in the 2020 source population at the regional level. A final trimming excluded all observations with weights exceeding the 99th percentile.

Since the information on the number of rooms in the housing unit was only asked in a second survey in June 2020 , this information was missing for the $22 \%$ of the sample who didn't complete the second questionnaire. We imputed this data using predictions obtained by logistic regression.

Sociodemographic area characteristics (size of the agglomeration and region), number of individuals living in the household per room, educational level, nationality (French or not French), professional status, smoking, body mass index, health status (chronic diseases) were described and compared using Chi2 tests between the three possible COVID-19 infection groups. We then conducted a multinomial logistic regression to compare the risk of infection before (reference category) and during the lockdown according to social class, with successive and additional adjustments for other socio-demographic and health factors. The final model presents the variables that allow us to test our hypotheses on the effect of living conditions: housing, social class and professional status. 
All analyses were performed using $\mathrm{R}$ software ( $\mathrm{R}$ 3.6.1). A $P$-value $<0.05$ was considered statistically significant. All percentages are weighted to account for the complex sampling design and post stratification.

Multivariable analyses were performed on unweighted data.

\section{Role of the funding source}

The funders had no role in the design, analysis, interpretation or writing. All the authors had full access to all the data and NB and FC had final responsibility for the decision to submit for publication.

\section{Results}

Table 1 describes the sociodemographic and health characteristics distribution of study participants and the frequency of possible COVID-19, according to the probable date of infection.

The sample was equally divided between men (47.6\%) and women (52.4\%) and the mean age was 43.50 years (95\%CI: 43.17-43.83). More than a third (38.8\%) of the sample lived in cities with more than 1,000,000 inhabitants while a minority (6.9\%) lived in rural areas. About a third of the sample (32.7\%) were considered upper class while $21.8 \%$ were working class. $15.3 \%$ of the sample had in person professional activities during the lockdown period.

Altogether, 13.0\% (95\% CI: 12.0-14.0\%) of participants reported symptoms compatible with possible cases of COVID-19 $(n=1335)$ in the 2 weeks preceding the survey.

Residents from the Paris region (Ile-de-France) $(P=$ 0.02), participants facing financial difficulties $(P=0.046)$ and those who reported chronic conditions (asthma or respiratory pathologies specifically) $(P=0.0001)$ were more likely to report possible COVID-19 while older participants $(P=0.003)$, and those who did not work before lockdown $(P=0.033)$ were less likely to report those symptoms. Reporting possible COVID-19 was unrelated to social class.

While the percentage of participants reporting possible COVID-19 infection during lockdown was lower than participants reporting possible COVID-19 infection before lockdown $(5.0 \%$ versus $8.0 \%, P=0.001)$, this decrease was uneven across social groups. As shown in Fig. 1, the decline was most pronounced among privileged classes (from $8.8 \%$ before lockdown to $4.3 \%$ during lockdown, $P=0.001$ ) while the decline was least pronounced among the working class (from $6.9 \%$ before lockdown to $5.5 \%$ during lockdown, $P=0.03$ ).

In addition, those living in housings with less than one room per person were slightly more likely to report a possible case of COVID-19 than others $(16.3 \%$ versus
$12.8 \%, P=0.08$ ), with no difference between before and during lockdown.

The multivariable analyses presented in Table 2 indicated that the odds of no infection relative to probable infection prior to lockdown was unrelated to social class but depended on the region of residence, with increased odds among residents from the Hauts-de-France region relative to those residing in the Paris region (Ile de France) $(\mathrm{OR}=1.39$; 95\% CI: $1.13-1.71, P=0.002)$.

Regarding the risk of infection during lockdown relative to the risk of infection before lockdown, it was higher among participants who had in-person professional activities compared to those who worked remotely (OR $=1.53$; 95\% CI: $1.03-2.29, P=0.037)$. This risk was also increased among working class compared to upper class participants $(\mathrm{OR}=1.57$; 95\% CI: $1.00-2.48, P=$ 0.051). It is worth noting that the odds-ratio for working class was 1.53 (95\% CI: $0.96-2.42, P=0.071)$ when adjusting for smoking and it was 1.49 (95\%CI: 0.93-2.40, $P=0.096$ ) when adjusting for history of chronic disease and obesity. Finally, this odds-ratio was reduced to 1.43 (95\% CI: $0.90-2.28, P=0.128$ ) when adjusting for perceived financial situation.

\section{Discussion}

To our knowledge, SAPRIS is the largest general population-based COVID-19 study in Europe that simultaneously collects detailed data on symptoms and social characteristics to investigate the impact of lockdown on possible COVID-19 infections.

Analyses by time period, corresponding to whether individuals may have been infected before or during lockdown, show differential trends by social class that were masked in an overall analysis. The issue of temporality is essential because confinement measures affected individuals differently according to their housing and working conditions $[5,20]$. Individuals at the top of the social hierarchy saw a greater decline in COVID-19 symptoms after the lockdown than those from the working class. In fact, working-class individuals were more likely than those in the upper class to have been infected during lockdown rather than before.

Our results show that this overexposure during lockdown was partly a result of their health status and lifestyle (smoking and history of chronic disease and obesity) since the OR for the working class slightly decreased after adjustment for these variables. Likewise, it was also partly an effect of their economic precariousness since the OR of the working class decreased when it was adjusted for this variable. The latter result is consistent with economists' work that has recently established that "the prevalence of the epidemic was higher in the poorer communes in France [21]. We also found that living in housing with less than one room per 
Table 1 Participants characteristics and associated proportion of possible COVID-19 by period

\begin{tabular}{|c|c|c|c|c|c|c|}
\hline & $\begin{array}{l}\text { Weighted } \\
\text { distribution }\end{array}$ & $\begin{array}{l}\text { likely } \\
\text { infection }\end{array}$ & P-Value* & $\begin{array}{l}\text { likely infection } \\
\text { prior the lockdown }\end{array}$ & $\begin{array}{l}\text { likely infection } \\
\text { during the } \\
\text { lockdown }\end{array}$ & $P$-Value** \\
\hline Age & & & 0.003 & & & 0.002 \\
\hline $18-34$ & $25.2(1759)$ & $13.8(232)$ & & $8.3(145)$ & $5.5(87)$ & \\
\hline $35-44$ & 29.7 (3028) & $14.8(425)$ & & $8.3(267)$ & $6.6(158)$ & \\
\hline $45-54$ & $25.8(2816)$ & $12.6(378)$ & & $8.7(268)$ & $3.9(110$ & \\
\hline $55-64$ & $19.3(2498)$ & $9.7(269)$ & & $6.2(193)$ & $3.5(76)$ & \\
\hline Sex & & & 0.947 & & & 0.783 \\
\hline Female & $52.4(5164)$ & $13(663)$ & & $8.2(442)$ & $4.8(221)$ & \\
\hline Male & $47.6(4937)$ & $13(641)$ & & $7.8(431)$ & $5.2(210)$ & \\
\hline Nationality & & & 0.437 & & & 0.709 \\
\hline French & $96.1(9703)$ & $13.1(1263)$ & & $8.1(842)$ & $5.1(421)$ & \\
\hline Not french & $3.9(348)$ & $11.3(37)$ & & $7.3(28)$ & $4(9)$ & \\
\hline Social Class & & & 0.965 & & & 0.234 \\
\hline Upper class & $32.7(5541)$ & $13(718)$ & & $8.8(500)$ & $4.3(218)$ & \\
\hline Upper middle class & $20.9(2397)$ & $12.9(303)$ & & $8.5(205)$ & $4.4(98)$ & \\
\hline Lower middle class & $18.1(894)$ & $13.4(114)$ & & $8(72)$ & $5.4(42)$ & \\
\hline Working class & $21.8(838)$ & $12.4(108)$ & & $6.9(66)$ & $5.5(42)$ & \\
\hline Health professional & $6.5(431)$ & $13.9(61)$ & & $6.2(30)$ & $7.7(31)$ & \\
\hline Professional status & & & 0.018 & & & 0.002 \\
\hline Unemployed at the time of lockdown's onset & $24.5(2178)$ & $10.6(241)$ & & $7.2(177)$ & $3.5(64)$ & \\
\hline Employed and stopped working since COVID & $18.0(1185)$ & $15.7(181)$ & & $10.3(116)$ & $5.4(65)$ & \\
\hline Full time teleworking & $38.8(5469)$ & $12.9(719)$ & & $8.1(492)$ & $4.7(227)$ & \\
\hline in-person professional activities & $18.7(1269)$ & $13.7(163)$ & & $6.6(88)$ & $7.1(75)$ & \\
\hline Overcrowding & & & 0.077 & & & 0.183 \\
\hline less or equal than one pers./room & $94.4(9557)$ & $12.8(1210)$ & & $7.9(816)$ & $4.9(394)$ & \\
\hline more than one pers./room & $5.6(544)$ & $16.3(94)$ & & $9.5(57)$ & $6.7(37)$ & \\
\hline Financial resources & & & 0.046 & & & 0.077 \\
\hline At ease & $29.5(4082)$ & $12.8(493)$ & & $8.3(346)$ & $4.5(147)$ & \\
\hline No particular problem & $46.5(4369)$ & $12.1(563)$ & & $7.5(382)$ & $4.5(181)$ & \\
\hline Difficult & $24.1(1581)$ & $15.2(238)$ & & $8.7(138)$ & $6.6(100)$ & \\
\hline Region & & & 0.02 & & & 0.006 \\
\hline Ile-de-France & $38.7(5195)$ & $14.4(714)$ & & $8.9(482)$ & $5.5(232)$ & \\
\hline Grand Est & $30.6(2854)$ & $13.4(368)$ & & $9.1(257)$ & $4.3(111)$ & \\
\hline Hauts-de-France & 30.7 (2052) & $10.9(222)$ & & $5.8(134)$ & $5.1(88)$ & \\
\hline Agglomeration size & & & 0.21 & & & 0.268 \\
\hline Rural area & $6.9(488)$ & $15.2(67)$ & & $10.1(47)$ & $5.1(20)$ & \\
\hline$<50,000$ & $4.3(335)$ & $12(44)$ & & $7.3(30)$ & $4.7(14)$ & \\
\hline $50-200,000$ & $8.2(536)$ & $11.6(67)$ & & $7.5(49)$ & $4.1(18)$ & \\
\hline $200-500,000$ & 17.1 (1972) & $10.9(229)$ & & $7.6(157)$ & $3.3(72)$ & \\
\hline $500,000-1,000,000$ & $24.8(1564)$ & $12.2(180)$ & & $6.5(106)$ & $5.6(74)$ & \\
\hline$>1,000,000$ & $38.8(5200)$ & $14.4(715)$ & & $8.9(482)$ & $5.5(233)$ & \\
\hline Chronic disease & & & $<0.0001$ & & & $<0.0001$ \\
\hline None & 77.7 (7923) & $12.9(1001)$ & & $7.8(664)$ & $5(337)$ & \\
\hline Hypertension & $4.7(455)$ & $10.2(54)$ & & $4.7(33)$ & $5.5(21)$ & \\
\hline
\end{tabular}


Table 1 Participants characteristics and associated proportion of possible COVID-19 by period (Continued)

\begin{tabular}{|c|c|c|c|c|c|c|}
\hline & $\begin{array}{l}\text { Weighted } \\
\text { distribution }\end{array}$ & $\begin{array}{l}\text { likely } \\
\text { infection }\end{array}$ & $P$-Value* & $\begin{array}{l}\text { likely infection } \\
\text { prior the lockdown }\end{array}$ & $\begin{array}{l}\text { likely infection } \\
\text { during the } \\
\text { lockdown }\end{array}$ & $P$-Value $* *$ \\
\hline Asthma or other respiratory diseases & $2.6(246)$ & $28.8(61)$ & & $19.2(44)$ & $9.6(17)$ & \\
\hline $\begin{array}{l}\text { Diabetes, cancer, heart disease, heart disease, } \\
\text { immune diseases, liver, kidney, immunity, }\end{array}$ & $2.4(257)$ & $12.6(34)$ & & $10(24)$ & $2.6(10)$ & \\
\hline Others & $12.7(1220)$ & $11.8(154)$ & & $7.5(108)$ & $4.3(46)$ & \\
\hline Active smoking & & & 0.807 & & & 0.856 \\
\hline Yes, daily & $11.7(819)$ & $12.9(93)$ & & $7.3(57)$ & $5.6(36)$ & \\
\hline Yes, sometimes (less than once a day) & $4.6(348)$ & $11.3(43)$ & & $6.2(26)$ & $5.1(17)$ & \\
\hline No & $83.8(8727)$ & $13.1(1136)$ & & $8.1(770)$ & $4.9(366)$ & \\
\hline Obesity & & & 0.811 & & & 0.448 \\
\hline $\mathrm{BMI}<30$ & $85.9(8889)$ & $12.9(1133)$ & & $7.8(758)$ & $5.1(375)$ & \\
\hline $\mathrm{BMI} \geq 30$ & $14.1(868)$ & $13.3(124)$ & & $9.1(84)$ & $4.1(40)$ & \\
\hline $\begin{array}{l}\text { Individual preventive measures } \\
\text { (mask, gel, social distancing) during outings in } \\
\text { the last } 7 \text { days. }\end{array}$ & & & $<0.0001$ & & & $<0.0001$ \\
\hline All 3 & $27(2797)$ & $16.2(413)$ & & $9.7(277)$ & $6.5(136)$ & \\
\hline At least one & $63(6355)$ & $11.3(750)$ & & $7(497)$ & $4.4(253)$ & \\
\hline None & $10(949)$ & $14.7(141)$ & & 10 (99) & $4.6(42)$ & \\
\hline All & $100(10,101)$ & 13.0 (1304) & & $8.0(873)$ & $5.0(431)$ & \\
\hline
\end{tabular}

${ }^{*}$ Chi2 test likely infection /no infection

${ }^{* *}$ Chi2 test between no infection/prior/during the lockdown

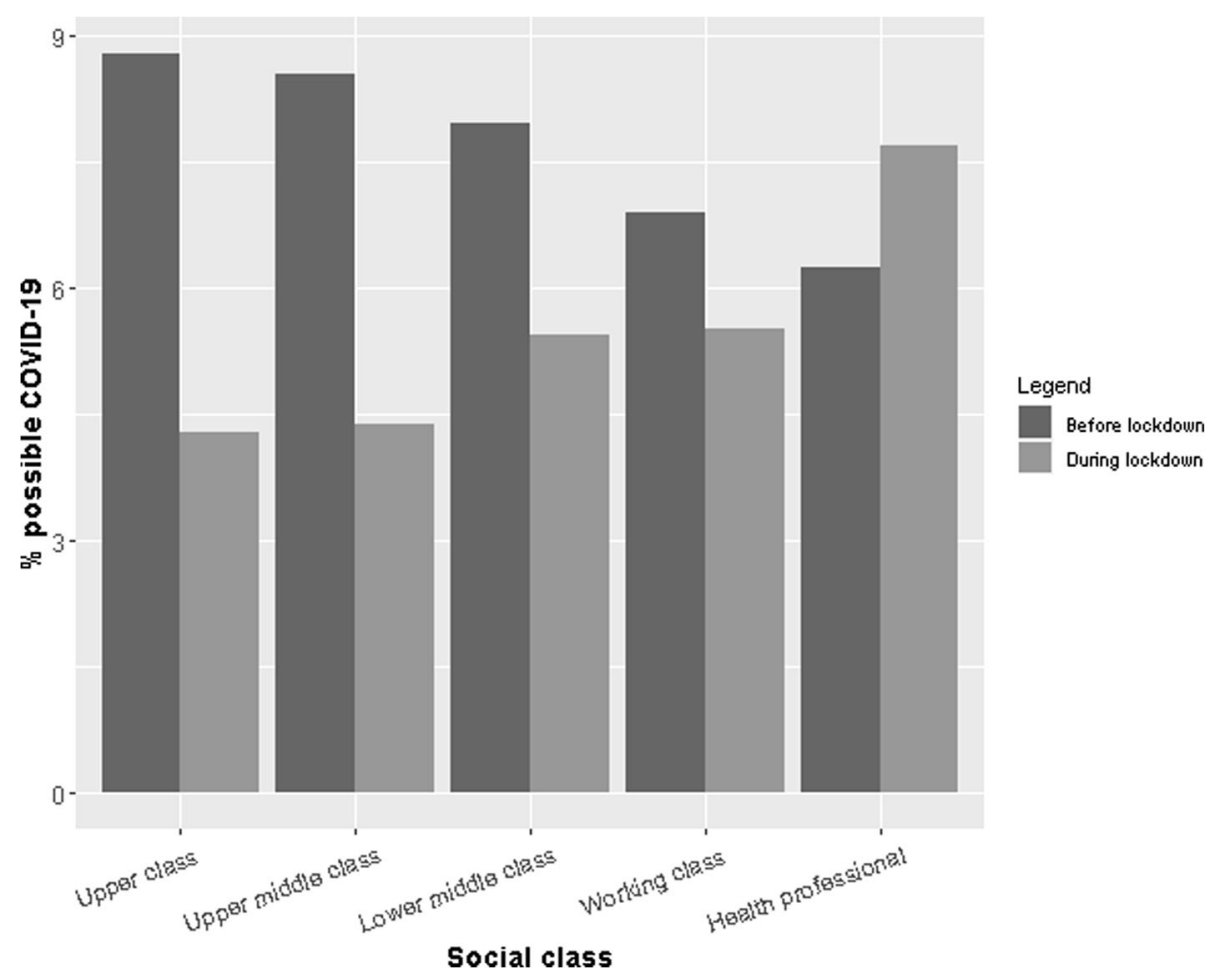

Fig. 1 Percentage of individuals likely to be infected before or during lockdown by social class 
Table 2 Factors associated with possible COVID-19: adjusted OR (95\% CI) Multinomial regression results Reference group: probable infection prior to the lockdown. OR adjusted for all the variables presented in the table

\begin{tabular}{|c|c|c|c|c|}
\hline & $\begin{array}{l}\text { no symptoms/likely } \\
\text { infection prior the } \\
\text { lockdown }\end{array}$ & $P$-Value & $\begin{array}{l}\text { likely infection during the } \\
\text { lockdown/likely infection } \\
\text { prior the lockdown }\end{array}$ & $P$-Value \\
\hline \multicolumn{5}{|l|}{ Age } \\
\hline $18-34$ & 1 & & 1 & \\
\hline $35-44$ & $0.95(0.77-1.17)$ & 0.622 & $1.00(0.72-1.38)$ & 0.99 \\
\hline $45-54$ & $0.87(0.71-1.07)$ & 0.198 & $0.69(0.49-0.97)$ & 0.035 \\
\hline $55-64$ & $1.09(0.86-1.37)$ & 0.475 & $0.73(0.49-1.07)$ & 0.101 \\
\hline \multicolumn{5}{|l|}{ Sex } \\
\hline Female & 1 & & 1 & \\
\hline Male & $1.00(0.86-1.15)$ & 0.95 & $1.03(0.82-1.30)$ & 0.809 \\
\hline \multicolumn{5}{|l|}{ Social Class } \\
\hline Upper class & 1 & & 1 & \\
\hline Upper middle class & $0.98(0.82-1.18)$ & 0.861 & $1.09(0.80-1.48)$ & 0.594 \\
\hline Lower middle class & $1.15(0.87-1.50)$ & 0.322 & $1.28(0.84-1.97)$ & 0.251 \\
\hline Working class & $1.11(0.83-1.49)$ & 0.467 & $1.57(1.00-2.48)$ & 0.051 \\
\hline Health professional & $1.05(0.69-1.61)$ & 0.82 & $1.66(0.91-3.04)$ & 0.098 \\
\hline \multicolumn{5}{|l|}{ Professional status } \\
\hline Unemployed at the time of lockdown's onset & 1 & & 1 & \\
\hline Employed and stopped working since COVID & $1.03(0.85-1.25)$ & 0.77 & $0.79(0.56-1.12)$ & 0.181 \\
\hline Full time teleworking & $0.84(0.67-1.05)$ & 0.126 & $1.11(0.78-1.58)$ & 0.568 \\
\hline in-person professional activities & $1.25(0.96-1.62)$ & 0.104 & $1.53(1.03-2.29)$ & 0.037 \\
\hline Overcrowding housing & $0.80(0.60-1.06)$ & 0.121 & $1.24(0.80-1.90)$ & 0.338 \\
\hline \multicolumn{5}{|l|}{ Region } \\
\hline Ile-de-France & 1 & & 1 & \\
\hline Grand Est & $0.99(0.83-1.18)$ & 0.924 & $0.84(0.63-1.13)$ & 0.258 \\
\hline Hauts-de-France & $1.39(1.13-1.71)$ & 0.002 & $1.26(0.91-1.74)$ & 0.168 \\
\hline
\end{tabular}

111 (1\%) participants excluded from the multivariate model due to missing values including 41 with possible COVID-19. Chronic disease, obesity, smoking and individual preventive measures are not presented in the final model since the odds ratio for the social class remained of the same magnitude (Supplementary Table 1)

person tended to be linked to the risk of having been infected. Finally, our results do not reflect a lower propensity of the working class to adopt individual prevention measures.

One can think that the overexposure to the virus of the working class during lockdown may reflect, at least in part, the fact that more individuals belonging to this class live in neighborhoods with high population density (Bajos et al. [22]). Such an effect is not completely captured by the size of the agglomeration. For example, the density in some neighborhoods in the Paris suburbs, where excess mortality by COVID-19 is particularly high, is higher than that observed in larger cities (https://dashboard.covid19. data.gouv.fr/vue-d-ensemble?location=FRA). The association between population density and SARS-CoV-2 transmission rates is well established [23, 24]. Residents of these high-density cities might have had more difficulty avoiding close contacts while shopping, on the street or on public transport. In any case, the data suggest that working class individuals were less protected by the lockdown measures than the more privileged categories.

Our results also show that continuing to work outdoors is associated with an increased risk of infection during lockdown. This could result from an increased number of contacts during public transport to work and also with colleagues. Finally, the increase in possible COVID-19 among health care workers despite the diffusion of masks probably reflects the persistence of contact with patients highly contagious.

This analysis has several limitations. First, the sample is socially diverse but is not fully representative of the French population as it only represents three regions in France and respondents from the Constances cohort who have internet connectivity are not representative of all residents in France. In particular, the study fails to capture particularly vulnerable groups such as 
undocumented migrants and homeless people. The few studies that have been carried out on vulnerable populations clearly show the importance of social and economic resources in dealing with the epidemic $[8,11]$.

While the study provides information on social class based on education and employment, it doesn't capture other forms of social disadvantage including race and ethnicity that are shown to increase the risk of COVID-19 infection in many settings and the risk COVID-19 related mortality in France [3] and other countries [25-27].

Additionally, it should be noted that our analyses are based on reported symptoms rather than on biologically tested cases, thus excluding asymptomatic individuals. However, the shortage of tests did not permit the use of testing in this study conducted in the early stages of the pandemic, especially before lockdown, as the use of RTPCR testing was limited to patients with severe symptoms. The share of participants reporting symptoms compatible with possible cases of COVID-19 (13\%) may appears high with respect to the infection spread in France during the same period of reference. Nevertheless, these are symptoms/illness without virological confirmation. Furthermore, our study was performed in the three regions which were the most affected by the first wave of COVID-19 in France (with seroprevalence estimates in the range of 7 to $10-11 \%$ [16]). In other representative studies, possible COVID-19 symptoms largely exceeded seroprevalence. For example, in the Pollan's study [25], the seroprevalence was $5 \%$ and the rate of participants reporting possible COVID-19 symptoms was $14 \%$.

Another limitation relates to the fact that some people may have had COVID-19 symptoms prior to the 15 days of the survey and are not counted in our possible COVID-19 cases. Since the socio-demographic structure of the respondents is stable during the study period (not shown), it is reasonable to think that the de facto exclusion of these situations does not affect results on association of possible Covid19 with social class.

In addition, although symptom reporting may risk being socially differentiated, it is reasonable to assume that any social reporting bias does not vary during the month of the survey.

In any case, from a prevention perspective, it is important to characterise the most exposed social groups and to try to uncover the social logics that favour this exposure, particularly those referring to living conditions $[28,29]$.

In conclusion, we showed that the effect of a lockdown policy designed and applied without taking into account social characteristics can contribute to increasing social inequalities in exposure to the risk of contracting the virus, as was rightly pointed out recently by several authors [30-32]. In this sense, the biomedical approach to prevention, which promotes preventive measures based on clinical knowledge without taking into account the socially differentiated effects of living conditions shows its limits, as was the case in the fight against previous epidemics $[9,33]$. Our results call for the implementation of future preventive policies that tackle these social inequalities. Such implementation is critical to reduce social inequalities related to COVID-19, as working-class individuals also have the highest COVID-19 related mortality, due to higher prevalence of comorbidities [11].

\section{Supplementary Information}

The online version contains supplementary material available at https://doi. org/10.1186/s12889-021-10521-5.

Additional file 1: Supplementary Table 1. Factors associated with possible COVID-19: adjusted OR (95\% Cl) Multinomial regression results. Additional adjustments on chronic disease, obesity, smoking and individual preventive measures.

\section{Acknowledgments}

The authors warmly thank all the volunteers of the Constances cohort. We thank the staff of the Constances cohort that have worked with dedication and engagement to collect and manage the data used for this study and to ensure continuing communication with the cohort participants. We thank A Sireyjol and L Kuhn for their help in statistical analysis and Pr J Bouyer for his advice in multivariable analysis.

We thank Rosalind Bell-Aldeghi for her help in editing the manuscript. *The SAPRIS study group.

The SAPRIS study group: Nathalie Bajos (co-Principal investigator), Fabrice Carrat (co-Principal investigator), Pierre-Yves Ancel, Marie-Aline Charles, Florence Jusot, Claude Martin, Laurence Meyer, Alexandra Rouquette, Ariane Pailhé, Gianluca Severi, Alexis Spire, Mathilde Touvier, Marie Zins.

\section{Data statement}

Data was the data taken from participants. The datasets used and analyzed during the current study are available from the corresponding author on reasonable request.

\section{Contributor and guarantor information}

Dr. Bajos, guarantor, had full access to all the data in the study and took responsibility for the integrity of the data and the accuracy of the data analysis. She accepts full responsibility for the work and/or the conduct of the study, had access to the data, and controlled the decision to publish. She attests that all listed authors meet authorship criteria and that no others meeting the criteria have been omitted.

Study concept and design: Bajos, Carrat.

Acquisition of data: Zins.

Analysis and interpretation of data: Bajos, Jusot, Pailhé, Spire, Martin, Meyer. Drafting of the manuscript: Bajos.

Critical revision of the manuscript for important intellectual content: All authors. Statistical analysis: Franck.

Obtained funding: Bajos, Carrat, Zins.

Administrative, technical, or material support: Lydié.

Study supervision: Bajos and Carrat.

\section{Copyright/license for publication}

The Corresponding Author has the right to grant on behalf of all authors and does grant on behalf of all authors, a worldwide licence to the Publishers and its licensees in perpetuity, in all forms, formats and media (whether known now or created in the future), to i) publish, reproduce, distribute, display and store the Contribution, ii) translate the Contribution into other languages, create adaptations, reprints, include within collections and create summaries, extracts and/or, abstracts of the Contribution, iii) create any other derivative work(s) based on the Contribution, iv) to exploit 
all subsidiary rights in the Contribution, v) the inclusion of electronic links from the Contribution to third party material where-ever it may be located and, vi) licence any third party to do any or all of the above.

\section{Authors' contributions}

The author(s) read and approved the final manuscript.

\section{Funding}

This study.

ANR (Agence Nationale de la Recherche, \#ANR-20-COVI-000, \#ANR-10-COHO-06), INSERM (Institut National de la Santé et de la Recherche Médicale, \#C20-26). Cohort funding.

The CONSTANCES Cohort Study is supported by the Caisse Nationale d'Assurance Maladie (CNAM), the French Ministry of Health, the Ministry of Research, the Institut National de la Santé et de la Recherche Médicale (INSE RM). CONSTANCES benefits from a grant from the French National Research Agency [grant number ANR-11-INBS-0002]

\section{Declaration}

\section{Competing interests}

All authors have completed the ICMJE uniform disclosure form at www. icmje.org/coi_disclosure.pdf and declared no support from any organisation for the submitted work; no financial relationships with any organisations that might have an interest in the submitted work in the previous 3 years; no other relationships or activities that could appear to have influenced the submitted work

\section{Author details}

${ }^{1}$ Institut de Recherche Interdisciplinaire sur les enjeux Sociaux - Sciences sociales, politique, santé, IRIS (UMR 8156 CNRS - EHESS - U997 INSERM), 5 cours des humanités, 93322 Aubervilliers, France. ${ }^{2}$ Paris Dauphine University, Paris, France. ${ }^{3}$ National Institute for Demographic Studies, Paris, France. ${ }^{4}$ French National Centre for Scientific Research, Paris, France. ${ }^{5}$ University of Paris Sud, Paris, France. ${ }^{6}$ Santé publique France, Paris, France. ${ }^{7}$ Sorbonne University, Paris, France.

Received: 4 November 2020 Accepted: 16 February 2021

Published online: 12 April 2021

\section{References}

1. Marmot M, Bell R. Social inequalities in health: a proper concern of epidemiology. Ann Epidemiol. 2016;26(4):238-40.

2. Salje H, Tran Kiem C, Lefrancq N, Courtejoie N, Bosetti P, Paireau J, Andronico A, Hoze N, Richet J, Dubost CL, Le Strat Y, Lessler J, Levy-Bruhl D, Fontanet A, Opatowski L, Boelle PY, Cauchemez S. Estimating the burden of SARS-CoV-2 in France. Science. 2020.

3. Papon S, Robert-Bobée I. Une hausse des décès deux fois plus forte pour les personnes nées à l'étranger que pour celles nées en France en mars-avril 2020. Insee Focus No 198 - juillet 2020.

4. Williamson EJ, et al. OpenSAFELY: factors associated with COVID-19 death in 17 million patients. Nature. 2020. https://doi.org/10.1038/s41586-020-2521-4.

5. Baker MG, Peckham TK, Seixas NS. Estimating the burden of United States workers exposed to infection or disease: a key factor in containing risk of COVID-19 infection. PLoS One. 2020;15(4):e0232452. https://doi.org/10.1371/ journal.pone.0232452.

6. Shadmi E, Chen Y, Dourado I, Faran-Perach I, Furler J, Hangoma P, Hanvoravongchai P, Obando C, Petrosyan V, Rao C, Ruano A, Shi L, Eugenio de Souza L, Spitzer-Shohat S, Sturgiss E, Suphanchaimat R, Villar Uribe M, Willems S. Health equity and COVID-19: global perspectives. Int J Equity Health. 2020;19(1):104. https://doi.org/10.1186/s12939-020-01218-z.

7. Wang Z, Tang K. Combating COVID-19: health equity matters. Nat Med. 2020;26:458-64. https://doi.org/10.1038/s41591-020-0823-6.

8. Okonkwo NE, Aguwa UT, Jang M, et al. COVID-19 and the US response: accelerating health inequities. BMJ Evid Based Med. 2020. https://doi.org/1 0.1136/bmjebm-2020-111426 [published online ahead of print, 2020 Jun 3].

9. Bambra C, Riordan R, Ford J, Matthews F. The COVID-19 pandemic and health inequalities. J Epidemiol Community Health. 2020. https://doi.org/1 $0.1136 /$ jech-2020-214401
10. Chung R, Dong D, Ming LM. Socioeconomic gradient in health and the covid-19 outbreak. BMJ, 2020;369. https://doi.org/10.1136/bmj.m1329 (Published 01 April 2020) Cite this as: BMJ 2020;369:m1329.

11. Wright L, Steptoe A, Fancourt D. Are we all in this together? Longitudinal assessment of cumulative adversities by socioeconomic position in the first 3 weeks of lockdown in the UK. J Epidemiol Community Health. 2020. https://doi.org/10.1136/jech-2020-214475 [published online ahead of print, 2020 Jun 5].

12. Flaxman S, Mishra S, Gandy A, Unwin HJT, Mellan TA, Coupland H, Whittaker C, Zhu H, Berah T, Eaton JW, Monod M, Imperial College C-RT, Ghani AC, Donnelly CA, Riley SM, Vollmer MAC, Ferguson NM, Okell LC, Bhatt S. Estimating the effects of non-pharmaceutical interventions on COVID-19 in Europe. Nature. 2020;584(7820):257-61. https://doi.org/10.1038/s41586-02 0-2405-7.

13. Khalatbari-Soltani S, Cumming RC, Delpierre C, Kelly-Irving M. Importance of collecting data on socioeconomic determinants from the early stage of the COVID-19 outbreak onwards. J Epidemiol Community Health. 2020;74(8): 620-3. https://doi.org/10.1136/jech-2020-214297.

14. Zins M, Goldberg M. Team C. the French Constances population-based cohort: design, inclusion and follow-up. Eur J Epidemiol. 2015;30(12):1317-28.

15. European Center for Diseases Control (ECDC). Case definition for coronavirus disease 2019 (COVID-19), as of 29 May 20202020 [Available from: https://www.ecdc.europa.eu/en/covid-19/surveillance/case-definition. Accessed 15 July 2020.

16. Carrat F, Touvier M, Severi G, Meyer L, Jusot F, Lapidus N, Rahib D, Lydié N, Charles MA, Ancel PY, Rouquette A, de Lamballerie X, Zins M, Bajos N; SAPR IS study group. Incidence and risk factors of COVID-19-like symptoms in the French general population during the lockdown period: a multi-cohort study. BMC Infect Dis. 2021;21(1):169. https://doi.org/10.1186/s12879-02105864-8.

17. McAloon C, Collins Á, Hunt K, et al. Incubation period of COVID-19: a rapid systematic review and meta-analysis of observational research. BMJ Open. 2020;10(8):e039652.

18. Lauer SA, Grantz KH, Bi Q, et al. The incubation period of coronavirus disease 2019 (COVID-19) from publicly reported confirmed cases: estimation and application. Ann Intern Med. 2020;172(9):577-82. https://doi.org/10.732 6/M20-0504.

19. Deville JC, Särndal CE, Sautory O. Generalized raking procedure in survey sampling. J Am Stat Assoc. 1993;88:1013-20.

20. Chen T, Krieger N. Revealing the unequal burden of COVID-19 by income, race/ethnicity, and household crowding: US county vs. ZIP code analyses. HCPDS Working Paper Volume 19, Number 1. April 21; 2020.

21. Brandily P, Brébion C, Briole S, Khoury L. A Poorly Understood Disease? The Unequal Distribution of Excess Mortality Due to COVID-19 Across French Municipalities. 2020. halshs-02895908.

22. Bajos N, Warszawski J, Pailhé A, Counil E, Jusot F. Les inégalités sociales au temps du COVID-19. Quest Santé Publique. 2020; https://www.sa ntepubliquefrance.fr/maladies-et-traumatismes/maladies-et-infections-respira toires/infection-a-coronavirus/documents/article/les-inegalites-sociales-autemps-du-covid-19.

23. Tammes P. Social distancing, population density, and spread of COVID-19 in England: a longitudinal study. BJGP Open. 2020;4(3). https://doi.org/10.3399/ bjgpopen20X101116 Published 2020 Aug 25.

24. Rubin D, Huang J, Fisher BT, et al. Association of Social Distancing, Population Density, and Temperature With the Instantaneous Reproduction Number of SARS-CoV-2 in Counties Across the United States. JAMA Netw Open. 2020;3(7):e2016099. https://doi.org/10.1001/jamanetworkopen.2020.1 6099 Published 2020 Jul 1.

25. Pollán M, Pérez-Gómez B, Pastor-Barriuso R, et al. Prevalence of SARS-CoV-2 in Spain (ENE-COVID): a nationwide, population-based seroepidemiological study. Lancet. 2020;396(10250):535-44. https://doi.org/10.1016/S0140-6736(20)31483-5.

26. Bhala N, Curry G, Martineau A, Agyemang C, Bhopal R. Sharpening the global focus on ethnicity and race in the time of COVID-19. Lancet. 2020; 395(10238):1673-6. https://doi.org/10.1016/S0140-6736(20)31102-8.

27. Niedzwiedz CL, O'Donnell CA, Jani BD, et al. Ethnic and socioeconomic differences in SARS-CoV-2 infection: prospective cohort study using UK biobank. BMC Med. 2020;18:160. https://doi. org/10.1186/s12916-020-01640-8

28. Napier AD. Rethinking vulnerability through Covid-19. Anthropol Today. 2020;36(3):1-2. https://doi.org/10.1111/1467-8322.12571. 
29. Lancet T. Redefining vulnerability in the era of COVID-19. Lancet. 2020; 395:1089.

30. Anderson G, Frank JW, Naylor CD, Wodchis W, Feng P. Using socioeconomics to counter health disparities arising from the covid-19 pandemic. BMJ. 2020;369:m2149. https://doi.org/10.1136/bmj.m2149 Published 2020 Jun 8.

31. Blundell R, Costa DM, Joyce R, Xu X. COVID-19 and inequalities. Fisc Stud. 2020;41(2):291-319.

32. Bonacini L, Gallo G, Patriarca F. Identifying policy challenges of COVID-19 in hardly reliable data and judging the success of lockdown measures. J Popul Econ. 2021;34(1):275-301.

33. Peckham R. COVID-19 and the anti-lessons of history. Lancet. 2020. https:// doi.org/10.1016/S0140-6736(20)30468-2.

\section{Publisher's Note}

Springer Nature remains neutral with regard to jurisdictional claims in published maps and institutional affiliations.

Ready to submit your research? Choose BMC and benefit from:

- fast, convenient online submission

- thorough peer review by experienced researchers in your field

- rapid publication on acceptance

- support for research data, including large and complex data types

- gold Open Access which fosters wider collaboration and increased citations

- maximum visibility for your research: over $100 \mathrm{M}$ website views per year

At BMC, research is always in progress.

Learn more biomedcentral.com/submissions 